\title{
The influence of location, source, and emission type in estimates of the human health benefits of reducing a ton of air pollution
}

\author{
Neal Fann • Charles M. Fulcher • Bryan J. Hubbell
}

Received: 17 October 2008 / Accepted: 11 May 2009/Published online: 9 June 2009

(C) The Author(s) 2009. This article is published with open access at Springerlink.com

\begin{abstract}
The benefit per ton (\$/ton) of reducing $\mathrm{PM}_{2.5}$ varies by the location of the emission reduction, the type of source emitting the precursor, and the specific precursor controlled. This paper examines how each of these factors influences the magnitude of the $\$$ ton estimate. We employ a reduced-form air quality model to predict changes in ambient $\mathrm{PM}_{2.5}$ resulting from an array of emission control scenarios affecting 12 different combinations of sources emitting carbonaceous particles, $\mathrm{NO}_{x}, \mathrm{SO}_{x}, \mathrm{NH}_{3}$, and volatile organic compounds. We perform this modeling for each of nine urban areas and one nationwide area. Upon modeling the air quality change, we then divide the total monetized health benefits by the $\mathrm{PM}_{2.5}$ precursor emission reductions to generate $\$ /$ ton metrics. The resulting $\$ /$ ton estimates exhibit the greatest variability across certain precursors and sources such as area source $\mathrm{SO}_{x}$, point source $\mathrm{SO}_{x}$, and mobile source $\mathrm{NH}_{3}$. Certain \$/ton estimates, including mobile source $\mathrm{NO}_{x}$, exhibit significant variability across urban areas. Reductions in carbonaceous particles generate the largest $\$ /$ ton across all locations.
\end{abstract}

Keywords Benefit per ton $\cdot \mathrm{PM}_{2.5} \cdot$ Health benefits . BenMAP $\cdot \mathrm{CMAQ} \cdot \mathrm{RSM} \cdot \$$ /ton $\cdot$ Precursor $\cdot \mathrm{SO}_{x}, \mathrm{NO}_{x}$, $\mathrm{NH}_{3}$, VOC, carbonaceous particles · Industrial point sources - Electrical generating units - Area sources . Mobile sources $\cdot$ Air pollution · Population exposure . Spatial heterogeneity $\cdot$ Source $\cdot$ Emission type

N. Fann $(\bowtie) \cdot$ C. M. Fulcher · B. J. Hubbell

U.S. Environmental Protection Agency,

Office of Air Quality Planning and Standards,

Research Triangle Park, NC 27711, USA

e-mail: Fann.neal@epa.gov

\section{Introduction}

The estimated human health benefits of reducing ambient fine particulate matter are highly sensitive to the geographic location and type of $\mathrm{PM}_{2.5}$ precursor emissions and the characteristics of the emitting source. In this paper, we apply an innovative reduced-form air quality model to estimate changes in ambient $\mathrm{PM}_{2.5}$ resulting from a variety of emission control strategies applied to different classes of emission sources. We then estimate the monetized mortality and morbidity benefits of the resulting changes in ambient $\mathrm{PM}_{2.5}$ cross several U.S. urban areas and for the U.S. as a whole. Finally, for each strategy and in each urban area and for the U.S. as a whole, we divide the total monetized human health benefits by the emission precursor reductions to derive an array of benefit per ton ( $\$ /$ ton) metrics that are specific to location, type of source, and emission precursor. The resulting \$/ton estimates illustrate the strong influence that these three factors - location, source, and emission typeexert on total $\mathrm{PM}_{2.5}$ benefits.

A common approach to estimating $\mathrm{PM}_{2.5}$ human health benefit is to first estimate the air quality changes associated with some discrete number of emission control strategies using a photochemical grid model such as the Community Multiscale Air Quality Model (CMAQ; EPA 2006a, 2008). Having estimated the change in ambient $\mathrm{PM}_{2.5}$ air quality, the health impacts would be quantified using a tool such as the Environmental Benefits Mapping and Analysis Program (BenMAP; Abt Associates 2009) that applies health effect and economic valuation coefficients to estimate the benefits of an incremental air quality change; these coefficients are drawn (or transferred) from peer-reviewed epidemiological and economic studies whose study populations are (ideally) as similar as possible to the ones under consideration in the benefits analysis. The strength of this approach is that it can 
provide a refined estimate of the health benefits of a select number of alternate scenarios. However, this approach tends to be highly time- and resource-intensive and so is generally applied only for a limited number of policy scenarios.

Recognizing this limitation, the U.S. Environmental Protection Agency (EPA) and other federal agencies have sometimes used transfer coefficients to estimate the monetized benefits resulting from emission reductions. Previous EPA analyses (e.g., the 1997 Regulatory Impact Analysis [RIA] for the integrated pulp and paper rule) have developed national nonsource-specific \$/ton estimates that could be generalized from a study site to the estimated reductions in emissions for a number of policy sites. These national nonsource-specific \$/ton estimates have also seen use in the Office of Management and Budget's annual reports to the Congress on the costs and benefits of federal regulations (OMB 2007, 2008). This technique is essentially an extension of the approach described above, which applies transfer coefficients in the quantification of both health impacts and economic valuation.

However, this approach suffers from its own limitations, as it relies on several strong assumptions, including that populations, meteorology, and source attributes such as plant stack heights, emission exit velocity, topography, plant dimensions, and other factors at the policy site are identical (or at least similar enough) to those of the study site. If this assumption is violated, then the transfer values per ton will overestimate or underestimate actual $\$ /$ ton at the policy site. In this article, we explore the sources of this heterogeneity and propose an alternate model to estimating $\mathrm{PM}_{2.5} \$$ /ton metrics.

\section{Understanding the sources of heterogeneity in benefits per ton estimates}

More recent EPA analyses have developed \$/ton estimates for specific source classes and emission types as a means of addressing this variability. For example, in assessing the benefits of utility $\mathrm{PM}$ and $\mathrm{SO}_{2}$ reductions for the Industrial Boilers and Process Heaters NESHAP Rule, EPA developed \$/ton estimates based on modeling of PM and $\mathrm{SO}_{2}$ reductions for a well-characterized emissions inventory and applied these \$/ton estimates to estimate the benefits of a less-characterized set of sources (U.S. EPA 2004a). Another example is EPA's analysis of the recent Mobile Source Air Toxics Rule, which developed and applied \$/ton estimates based on air quality modeling conducted for the Clean Air Nonroad Diesel Rule (EPA 2004b). These estimates represented an improvement, but still failed to account for the role of geographic heterogeneity, which may be considerable.
Analyses by Levy et al. (1999, 2009) examined several estimates of the environmental costs of power plant emissions and concluded that there is the potential for significant heterogeneity in the environmental and health impacts per kilowatt hour of electricity generated. This heterogeneity is a product of source location, meteorology, mix of pollutants emitted, and atmospheric conditions, including baseline atmospheric concentrations of pollutants. While Levy et al. applied a case study methodology which fails to account fully for the potential impact of interactions among emission reductions from spatially dispersed sources, this research does suggest the importance of heterogeneity in benefits estimates - heterogeneity that should be properly reflected in $\$ /$ ton estimates.

Accounting for the key sources of heterogeneity is especially important when estimating the formation of, and the resulting benefits of reducing, fine particulate matter, or $\mathrm{PM}_{2.5}$. Three inter-related sources of heterogeneity affect the magnitude of $\mathrm{PM}_{2.5} \$ /$ ton estimates. The first relates to the chemical processes that govern the formation of $\mathrm{PM}_{2.5}$ in the atmosphere. Ambient $\mathrm{PM}_{2.5}$ is a complex mixture of primary and secondarily formed particles, resulting from chemical interactions in the atmosphere and physical transport of emissions of particulate matter precursors, including available $\mathrm{SO}_{2}, \mathrm{NO}_{x}$, and $\mathrm{NH}_{3}$, meteorology (particularly temperature), and baseline levels and composition of $\mathrm{PM}_{2.5}$. The complex nonlinear chemistry governing PM formation suggests that the impact of reducing precursor emissions could be very different across areas due to base conditions at both the emitting source and the receptor areas. As such, it is important to account for this variability when estimating the benefits of reducing a ton of $\mathrm{PM}_{2.5}$ precursor.

The second source of heterogeneity relates to the characteristics of the emitting source. The potential for transport of $\mathrm{PM}_{2.5}$ from particular sources to population centers will depend on the local and regional meteorology discussed above, but also on the characteristics of sources. These attributes include stack heights, stack temperatures, and velocity of emissions as they leave the stacks. Thus, some sources may have more inherent potential to emit precursors that will transport to population centers.

The third factor that may influence the heterogeneity in $\mathrm{PM}_{2.5}$-related \$/ton estimates is the size of the population exposed to $\mathrm{PM}_{2.5}$ and the susceptibility of that population to adverse health outcomes. For example, we would expect a larger \$/ton associated with a class of sources that emit large volumes of $\mathrm{PM}_{2.5}$ and that are located in close proximity to major population centers. Likewise, we might expect that the $\$ /$ ton would be larger for classes of sources located in proximity to populations whose susceptibility was greater for certain adverse health impacts such as respiratory outcomes. 


\section{Producing $\mathbf{P M}_{2.5}$ benefit per ton estimates that better account for key sources of heterogeneity}

The purpose of this analysis is to develop a matrix of $\$ /$ ton benefit transfer estimates that account for a variety of emission types, industry classifications, and locations and to examine the heterogeneity within that set of estimates. In addition to examining those factors highlighted by Levy et al. (1999, 2009), we also explore the influence of other factors that may lead to heterogeneity in the $\$ /$ ton of pollutant reduced, as described above. We focus on those factors influencing the heterogeneity in the incremental change in ambient $\mathrm{PM}_{2.5}$ concentration associated with a given amount of emissions among different urban areas, rather than factors related to health concentration-response functions or economic valuation estimates. We make use of EPA's response surface model (RSM), generated from the CMAQ, to estimate $\mathrm{PM}$ air quality $\mathrm{PM}_{2.5}$ ambient air concentration changes associated with emission reductions (EPA 2006b). The CMAQ model simulates the multiple physical and chemical processes involved in the formation, transport, and destruction of fine particulate matter and ozone (Byun and Schere 2006) and has been utilized for regulatory modeling applications (EPA 2006a, 2008). For ease of discussion, we translate these air quality changes into dollars using EPA's regulatory benefits analysis model, BenMAP (Abt Associates 2009). In this paper, we demonstrate that there is a substantial level of heterogeneity in the fine particulate matter $\left(\mathrm{PM}_{2.5}\right)$ air quality benefits associated with a ton of emission reductions across several dimensions, including type of precursor emission, source category, location, and levels of pollutants reduced.

For this analysis, we use the RSM to calculate the benefits of reducing ambient $\mathrm{PM}_{2.5}$ resulting from reductions in emissions of $\mathrm{NO}_{x}, \mathrm{SO}_{2}, \mathrm{NH}_{3}$, organic and elemental particles, and volatile organic compounds (VOC). The RSM allows users to model the air quality impacts of changes in emission levels within nine urban areas and a broad region encompassing the rest of the continental U.S outside of these nine urban areas. The RSM used in this study is based on air quality modeling using CMAQ version 4.4 with a $36-\mathrm{km}$ horizontal domain (148× 112 grid cells) and 14 vertical layers. The modeling domain encompasses the contiguous U.S. and extends from $126^{\circ}$ to $66^{\circ}$ west longitude and from $24^{\circ}$ to $52^{\circ}$ north latitude. A rigorous area-of-influence analysis was conducted for the selection of RSM urban locations to discern the degree of overlap between different urban areas in terms of air quality impacts and to tease out local versus regional impacts. The area-of-influence analysis identified nine urban areas where ambient $\mathrm{PM}_{2.5}$ is largely independent of the precursor emissions in all other included urban areas. Thus, selection of these areas allows the RSM to analyze air quality changes in these nine urban areas and associated counties independent of one another. These nine urban areas include New York/Philadelphia (combined), Chicago, Atlanta, Dallas, San Joaquin, Salt Lake City, Phoenix, Seattle, and Denver. The emissions baseline for all air quality modeled was the 2001 National Emissions Inventory projected to the year 2015. This inventory accounts for emission reductions from such national rules as the Clean Air Interstate Rule, the Nonroad Diesel Rule, and the Tier-2 Rule, among others. A complete description of CMAQ, meteorological, emission, and initial and boundary condition inputs used for this analysis are discussed in the technical support document for the U.S. EPA Clean Air Interstate Rule (EPA 2005).

We analyze local and regional strategies that reduce emissions by a fixed percentage. For example, one experimental run might reduce $\mathrm{NO}_{x}$ emissions by $50 \%$ in each of the nine urban areas, including Atlanta, Chicago, Dallas, Denver, New York/Philadelphia, Phoenix, Salt Lake City, San Joaquin Valley, and Seattle; we also estimate benefits from emission reductions nationwide, both within and outside of these nine urban areas. Figure 1 illustrates the location of the RSM urban areas across the U.S.

While there are many source categories, we aggregated source emissions to broader groups to reduce the number of model runs required. Certain precursor emissions from source categories were omitted where they were considered de minimus. For example, there are very low levels of ammonia emitted by electric utilities $(<1 \%$ of the total ammonia inventory), so no response surface factors were developed for ammonia from electric utilities. Table 1 provides a listing of the 12 source/pollutant combinations that were examined in the response surface modeling.

\section{Geographic Definition of Nine Urban Areas Modeled in Response Surface Model}

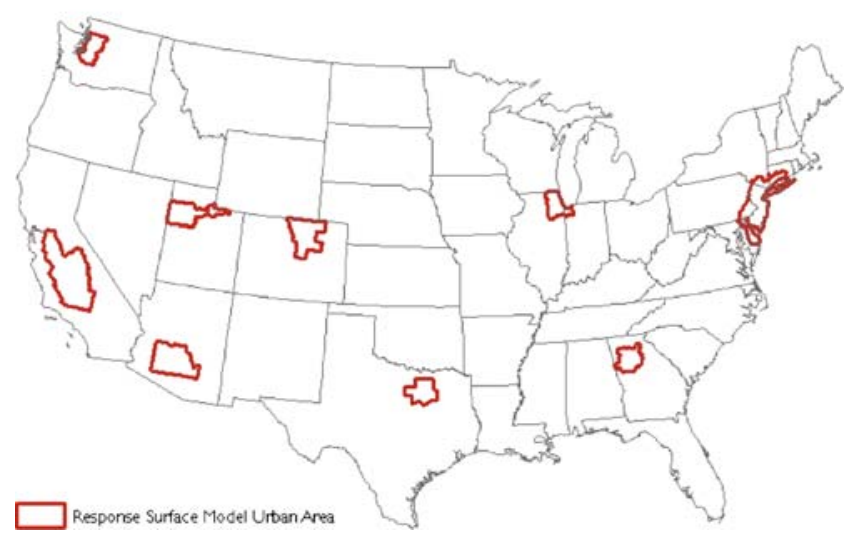

Fig. 1 The geographic definition of the nine RSM urban areas 
Table 1 Sources and emission types modeled in the RSM

\begin{tabular}{|c|c|c|c|c|c|}
\hline \multirow[t]{2}{*}{ Emissions } & \multicolumn{5}{|l|}{ Source types } \\
\hline & $\begin{array}{l}\text { Industrial } \\
\text { point sources }\end{array}$ & $\begin{array}{l}\text { Electrical } \\
\text { generating units }\end{array}$ & $\begin{array}{l}\text { Industrial point sources and } \\
\text { electrical generating units combined }\end{array}$ & $\begin{array}{l}\text { Area } \\
\text { sources }\end{array}$ & $\begin{array}{l}\text { Mobile } \\
\text { sources }\end{array}$ \\
\hline Primary organic and elemental carbon & & & $\mathrm{X}$ & $X$ & $\mathrm{X}$ \\
\hline $\mathrm{SO}_{x}$ & $X$ & $X$ & & $X$ & \\
\hline $\mathrm{NO}_{x}$ & $\mathrm{X}$ & $X$ & & & $\mathrm{X}$ \\
\hline $\mathrm{NH}_{3}$ & & & & $X$ & $X$ \\
\hline VOC & & & $X$ & & \\
\hline
\end{tabular}

\section{Generating the matrix of benefits per ton estimates}

Generation of a \$/ton value for PM precursors is a multistep process, illustrated in Fig. 2:

1. generate a set of air quality changes associated with a predetermined reduction in emissions for a specific emission type, location, and source using the CMAQ RSM,

2. model the human health benefits associated with the changes in air quality using BenMAP, and

3. divide the total benefits by the tons of emissions reduced.

We executed the first step by developing a set of emission reduction scenarios covering the complete set of

Scenario selection

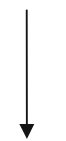

Response Surface Model estimate of air quality change across U.S. and 9 urban areas

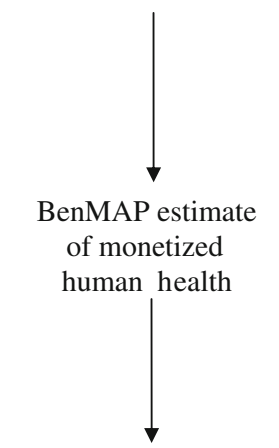

Divide total monetized benefits by scenario emission reductions abated

Fig. 2 The sequence of steps for calculating the $\$ /$ ton of reducing $\mathrm{PM}_{2.5}$ precursor emissions

Iterate for each scenario
12 emission/source combinations in the CMAQ RSM, evaluated at three reduction levels, $25 \%, 50 \%$, and $75 \%$, to allow for exploration of nonlinearities in the $\$ /$ ton estimates (for brevity of presentation and because nonlinearities were generally found to be small, we include only the results based on the $50 \%$ emission reductions).

We then modeled the grid level changes in $\mathrm{PM}_{2.5}$ associated with these emission reduction scenarios using the RSM, implemented through the PROC MIXED procedure in SAS 9.1. These gridded changes in ambient $\mathrm{PM}_{2.5}$ are then used as inputs to the BenMAP model to complete step 2 (Fig. 3).

To provide estimates of human health benefits for each emission reduction scenario, we load the changes in ambient $\mathrm{PM}_{2.5}$ estimated using the CMAQ RSM into the BenMAP. BenMAP is a Windows-based computer program that estimates the health benefits from improvements in air quality. BenMAP is primarily intended as a tool for
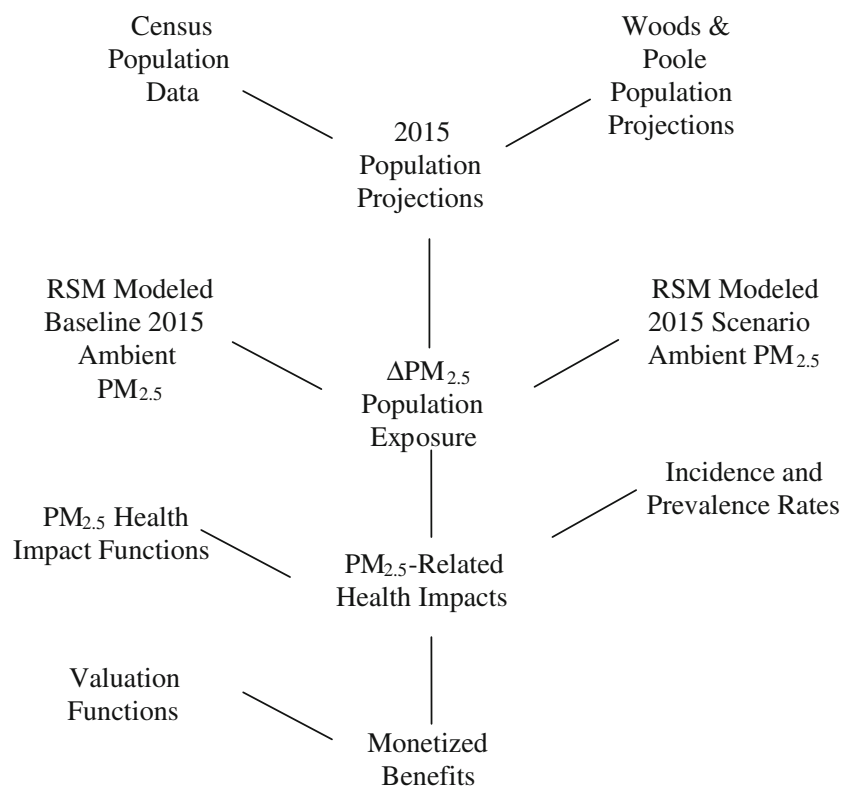

Fig. 3 The data inputs and model outputs for estimating the $\$$ ton of reducing $\mathrm{PM}_{2.5}$ precursor emissions 
estimating the health impacts and associated economic values of changes in ambient air pollution. It accomplishes this by running health impact functions, which relate a change in the concentration of a pollutant with a change in the incidence of a health endpoint. A typical health impact function might look like:

$\Delta y=y_{0} \times\left(e^{\beta \times \Delta x}-1\right)$

where $y_{0}$ is the baseline incidence (the product of the baseline incidence rate times the potentially affected population), $\beta$ is the effect estimate, and $\Delta x$ is the estimated change in the summary pollutant measure. For example, in the case of a premature mortality health impact function, we would utilize the following inputs:

- Air pollution change. The air quality change is calculated as the difference between the starting air pollution level, also called the baseline, and the air pollution level after some change, such as that caused by a regulation. In this exercise, we used the RSM to estimate the air pollution change.

- Mortality or morbidity effect estimate. The mortality or morbidity effect estimate is an estimate of the percentage change in mortality or morbidity due to a one unit change in ambient air pollution. For this analysis, we apply $\mathrm{PM}_{2.5}$ mortality effect coefficients drawn from the reanalysis of the American Cancer Society cohort (Pope et al. 2002) and the reanalysis of the Harvard Six Cities cohort (Laden et al. 2006). For ease of presentation, we present the derived results of Laden et al. (2006) only; estimates calculated using the effect coefficient of Pope et al. (2002) would be smaller. We do not apply threshold adjustments to any of the $\mathrm{PM}_{2.5}$ mortality or morbidity effect estimates. We also consider an array of morbidity health endpoints including cases of chronic bronchitis, nonfatal acute myocardial infarctions, and hospitalizations for respiratory symptoms. For the sake of brevity, we do not enumerate each of the epidemiological studies applied; readers interested in a comprehensive list of $\mathrm{PM}_{2.5}$ morbidity endpoints may consult EPA (2008).

- Mortality and morbidity incidence. The incidence rate is an estimate of the average number of people that suffer a given adverse health outcome in a given population over a given period of time. For example, the mortality incidence rate might be the probability that a person will die in a given year. For this analysis, we used county mortality rates from the CDC-WONDER database, projected to 2015; in this respect, we account for the variability in population vulnerability across the urban areas. BenMAP also contains baseline incidence rates for each morbidity endpoint. These rates are generally at the regional or national level; complete information may be found in the BenMAP user manual (Abt Associates 2008). When calculating health impacts, BenMAP allocates mortality and morbidity rates to the CMAQ grid cell.

- Exposed population. The exposed population is the number of people affected by the air pollution reduction. This analysis uses Woods and Poole's (2007) projections of census population to 2015 .

Finally, BenMAP calculates the economic value of health impacts. For example, after the calculation of the mortality change, the program values these premature deaths by multiplying the change in mortality reduction by an estimate of the value of a statistical life:

\section{Value mortality $=$ Mortality change

$$
\times \text { Value of statistical life }
$$

In this analysis, we applied a value of $\$ 6.2 \mathrm{M}$, which represents the default EPA value used in RIA's. BenMAP generated estimates of total monetized benefits for each of the model scenarios. Because of the very large number of RSM model scenarios, BenMAP was run in batch mode for each of the 81 scenarios. Each of these total monetized benefit estimates were then divided by the relevant total emission reductions to derive a $\$ /$ ton estimate.

\section{Results and discussion}

As Fig. 4 illustrates, the value of the \$/ton estimates varies by geographic location and $\mathrm{PM}_{2.5}$ precursor. The national $\$$ / ton estimates, found on the top row of the figure, are national-level averages that represent the benefits of $\mathrm{PM}_{2.5}$ precursor emission reductions from sources located throughout the United States, including the nine separately defined urban areas. As such, they essentially average out much of the geographic variability observed in specific locations. This is to say that spatial heterogeneity is masked in the national estimate because of the very large geographic area covered.

However, two sources of variability are apparent in the national estimates. First, there is a high degree of heterogeneity among the $\$ /$ ton by $\mathrm{PM}_{2.5}$ precursors. Clearly, reductions in directly emitted carbonaceous particles offer the largest $\$ /$ ton. This relatively large estimate is likely due to the fact that these particles are emitted as total $\mathrm{PM}_{2.5}$ and thus do not undergo any additional transformation in the atmosphere before affecting population centers. Moreover, carbonaceous particles tend to be emitted in close proximity to population centers. In fact, area source and mobile source carbona- 


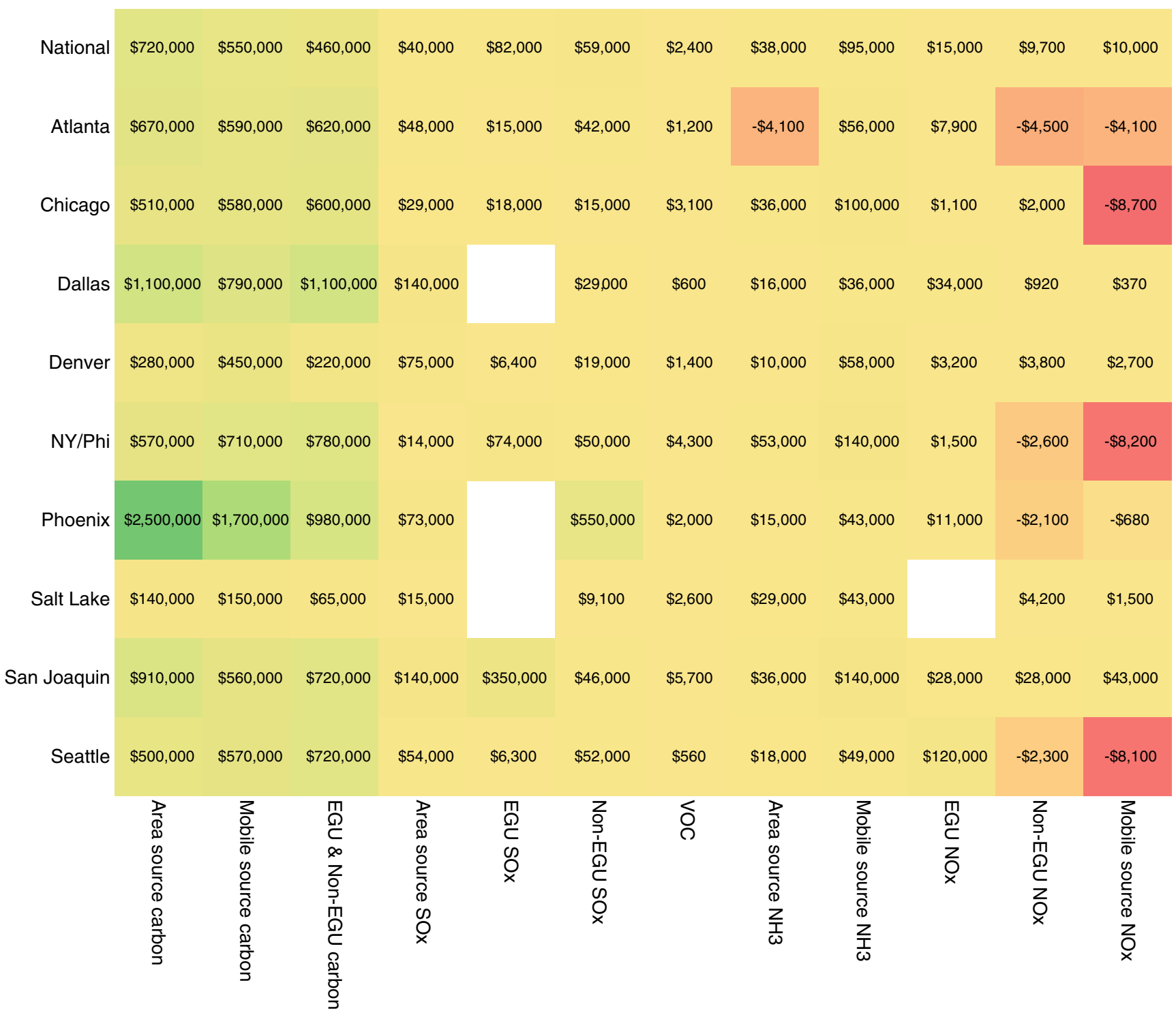

Fig. 4 The monetized \$/ton in 2015 of reductions in $\mathrm{PM}_{2.5}$ precursor emissions by area of the country (Laden et al. (2006) mortality estimate, $2006 \$, 3 \%$ discount rate)

ceous particle emissions, in particular, show the highest \$/ton-suggesting that the emissions and population centers exposed are colocated.

The next highest national \$/ton estimates are associated with emissions of $\mathrm{SO}_{2}$. These estimates are not as high as directly emitted carbonaceous particles likely due to the fact that, as a gas, $\mathrm{SO}_{2}$ must be transformed into particles, and this occurs over moderate to long transport distances from the source during which much of the $\mathrm{SO}_{2}$ is removed by wet or dry deposition before it is transformed. Both phenomena reduce the unit (per ton) impact on population centers near the source. Among the lowest $\$ /$ ton estimates is for $\mathrm{NO}_{x}$ reductions. An even smaller amount of $\mathrm{NO}_{x}$ is transformed into $\mathrm{PM}_{2.5}$ before it is removed than $\mathrm{SO}_{2}$. However, it should be noted that the $\$$ ton of $\mathrm{SO}_{x}$ and $\mathrm{NO}_{x}$ reflect the $\mathrm{PM}_{2.5}$-related benefits alone and does not consider any independent health impact associated with either $\mathrm{NO}_{2}$ or $\mathrm{SO}_{2}$ exposure.

The urban area-specific \$/ton estimates (Fig. 4) suggest a significant amount of inter-regional and intraregional variability. While reductions in directly emitted carbonaceous particles produce the highest $\$ /$ ton estimates in each of the nine areas, the magnitude of the benefit varies across the areas. Areas in the west, such as Phoenix, Salt Lake City, and San Joaquin, enjoy the largest $\$ /$ ton ratios for reductions of carbonaceous particles, while other urban areas see smaller ratios. These differences may be due to the baseline health status of populations in these areas. Alternately, urban areas with very large populations, such as the New York/Philadelphia area located in coastal areas, 
may see smaller $\$ /$ ton estimates as $\mathrm{PM}_{2.5}$ transports away from the city and toward unpopulated areas.

Other precursor- and source category-specific \$/ton ratios are far smaller by comparison and show some degree of variability. The smaller size may be due to the fact that the transformation of these precursors into total $\mathrm{PM}_{2.5}$ occurs downwind from the urban area. Certain precursors, such as mobile source $\mathrm{NH}_{3}$ and all-source VOC, exhibit a fairly consistent $\$$ /ton estimate across the urban areas. Others, such as mobile source $\mathrm{NO}_{x}$, show a disbenefit in eastern cities such as Chicago, New York/Philadelphia, and Atlanta; this is due to the well-documented NO titration of $\mathrm{O}_{3}$ effect where additional $\mathrm{NO}_{x}$ reductions in $\mathrm{NO}_{x}$-rich areas lessen the titration of $\mathrm{O}_{3}$. Under this $\mathrm{NO}_{x}$-rich situation, the formation of particulate nitrate is not limited to $\mathrm{NO}_{x}$, but to ozone and other oxidants (e.g., $\mathrm{OH}$ and $\mathrm{H}_{2} \mathrm{O}_{2}$ ). Less $\mathrm{NO}_{x}$ titration of $\mathrm{O}_{3}$ results in more $\mathrm{O}_{3}$ and oxidants available to oxidize $\mathrm{NO}_{x}$ to form $\mathrm{HNO}_{3}$, which subsequently react with $\mathrm{NH}_{3}$ to form more particulate nitrate (and thus disbenefit). It should be noted that, while $\mathrm{NO}_{x}$ reductions may occasionally generate $\mathrm{PM}_{2.5}$ disbenefits in certain urban areas, because $\mathrm{NO}_{x}$ is also an $\mathrm{O}_{3}$ precursor, additional $\mathrm{NO}_{x}$ reductions - even in areas where $\mathrm{PM}_{2.5}$ disbenefits are possible - may produce a downwind $\mathrm{O}_{3}$ benefit. Moreover, $\mathrm{NO}_{x}$ emission controls may also affect other copollutants, such as directly emitting $\mathrm{PM}_{2.5}$, that may result in a health benefit.

The results in Fig. 4 are sensitive to several key input parameters including the estimate of $\mathrm{PM}_{2.5}$-related mortality and the VSL, among others; as the science continues to evolve, these parameters are likely to change, affecting the magnitude of the benefit per ton estimates. For this reason, we encourage readers to consult the latest array of $\mathrm{PM}_{2.5}$ benefit per ton estimates available on EPA's website (www. epa.gov/air/benmap/bpt.html) that reflect the best available science.

\section{Limitations and uncertainties}

There are several key limitations and uncertainties associated with these $\$ /$ ton estimates:

- Care should be used when applying these estimates to urban areas other than those analyzed. As discussed above, the unique attributes of each urban area cause the $\$ /$ ton of emission reduction to vary by a significant amount. For this reason, there are special uncertainties incurred when transferring these metrics from one urban area to another.

- The \$/ton metrics contain each of the uncertainties inherent in a $P M_{2.5}$ benefits analysis. As discussed in the RIA for the $\mathrm{PM}_{2.5}$ National Ambient Air Quality
Standards (NAAQS; EPA 2006a, b), there are a variety of uncertainties associated with calculating PM benefits; these uncertainties are propagated through to the $\$ /$ ton estimates discussed in this article.

- These estimates omit certain benefits categories. Reductions in $\mathrm{PM}_{2.5}$ precursors may provide visibility benefits, which are not expressed in the $\$ /$ ton metrics. Certain unquantified benefit categories, described fully in the $\mathrm{PM}_{2.5}$ NAAQS RIA (EPA 2006a, b), are also omitted. Moreover, these metrics reflect the monetized health benefits of reductions in exposure to ambient $\mathrm{PM}_{2.5}$ alone and do not incorporate the benefits of reductions in other pollutants such as $\mathrm{O}_{3}, \mathrm{NO}_{2}$, or $\mathrm{SO}_{2}$.

A comprehensive benefits analysis frequently reports confidence intervals around the mean incidence and valuation estimates, which provide a limited degree of quantitative characterization of uncertainty around these mean values; these are based on the standard errors reported in the underlying epidemiology and economic valuation studies. When calculating \$/ton estimates, we use the mean monetized benefits estimate alone.

\section{Conclusions}

The $\mathrm{PM}_{2.5} \$ /$ ton estimates in this paper reflect three principal sources of heterogeneity:

- Variability across precursors. The \$/ton for certain pollutants, such as directly emitted $\mathrm{PM}_{2.5}$, is much higher than others. This is due to the differences among the precursors in their potential to form $\mathrm{PM}_{2.5}$, local atmospheric conditions, and proximity to populations.

- Variability across sources. Certain sources may emit a common precursor, but may produce very different $\$$ / ton estimates. These differences are likely due to variations in source parameters, such as stack height or exit velocity, which in turn influence subsequent dispersion of the pollutant and human exposure.

- Variability across location. The \$/ton for a given pollutant showed some degree of variation based on the urban area in which the pollutant was emitted. This is likely due to differences in atmospheric conditions among each of the nine urban areas as well as differences in population densities and baseline health status.

These \$/ton estimates account for many, but not all, of the important sources of heterogeneity associated with $\mathrm{PM}_{2.5}$ formation, transport, and human exposure across the nation and in a small number of urban areas. By accounting for these key sources of variability, these estimates can inform the development of air quality 
management plans. For example, the estimates demonstrate that emission control strategies affecting directly emitted particles promise to reduce ambient levels of $\mathrm{PM}_{2.5}$-and produce greater health benefits - than those reducing VOC emissions. However, maximizing net benefits will require users to consider both the benefit, and the cost, per ton of emission control. For example, while the benefits of reducing emissions of $\mathrm{SO}_{2}$ are significantly smaller than the per-ton benefits of reducing emissions such as directly emitted carbonaceous particles, controlling $\mathrm{SO}_{2}$ may be significantly less expensive. Thus, when applying these \$/ton metrics, analysts should consider both the expected benefits and costs.

Open Access This article is distributed under the terms of the Creative Commons Attribution Noncommercial License which permits any noncommercial use, distribution, and reproduction in any medium, provided the original author(s) and source are credited.

\section{References}

Abt Associates, Incorporated (2008) Users manual for the environmental Benefits Mapping and Analysis Program. Available at http://www.epa.gov/air/benmap/docs.html. Accessed 25 April 2009

Abt Associates, Incorporated (2009) Environmental Benefits Mapping and Analysis Program (Version 3.0). Prepared for the Environmental Protection Agency, Office of Air Quality Planning and Standards, Air Benefits and Cost Group, Research Triangle Park, NC

Byun DW, Schere KL (2006) Review of the governing equations, computational algorithms, and other components of the models-3 Community Multiscale Air Quality (CMAQ) Modeling System. Appl Mech Rev 59(2):51-77. doi:10.1115/1.2128636

Laden F, Schwartz J, Speizer FE (2006) Reduction in fine particulate air pollution and mortality. Am J Respir Crit Care Med 173:667672. doi:10.1164/rccm.200503-443OC

Levy JI, Hammitt JK, Yanagisawa Y (1999) Development of a new damage function model for power plants: methodology and applications. Environ Sci Technol 33:4364-4372. doi:10.1021/ es990634+
Levy JI, Baxter LK, Schwartz J (2009) Uncertainties and variability in health-related damages from coal-fired power plants in the United States. Risk Anal (in press)

Office of Management and Budget (2007) Report to Congress on the costs and benefits of federal regulations and unfunded mandates on state, local, and tribal entities. Available at http://www. whitehouse.gov/omb/inforeg/regpol-reports_congress.html. Accessed 17 October 2008

Office of Management and Budget (2008) Draft report to Congress on the costs and benefits of federal regulations and unfunded mandates on state, local, and tribal entities. Available at http:// www.whitehouse.gov/omb/inforeg/regpol-reports_congress.html. Accessed 17 October 2008

Pope CA, Burnett RT III, Thun MJ (2002) Lung cancer, cardiopulmonary mortality, and long-term exposure to fine particulate air pollution. JAMA 287:1132-1141. doi:10.1001/jama.287.9.1132

U.S. Environmental Protection Agency (1997) Final regulatory impact analysis: pulp and paper rule. Prepared by Office of Air and Radiation. Available at http://www.epa.gov/OST/pulppaper/jd/ pulp.pdf. Accessed 17 October 2008

U.S. Environmental Protection Agency (2004a) Final regulatory impact analysis: industrial boilers rule. Prepared by Office of Air and Radiation. Available at http://www.epa.gov/ttn/ecas/ regdata/RIAs/indboilprocheatfinalruleRIA.pdf. Accessed 17 October 2008

U.S. Environmental Protection Agency (2004b) Final regulatory impact analysis: clean air nonroad diesel rule. Prepared by Office of Air and Radiation. Available at http://www.epa.gov/nonroaddiesel/2004fr.htm\#ria. Accessed 17 October 2008

U.S. Environmental Protection Agency (2005) Technical support document for the final clean air interstate rule: air quality modeling; Office of Air Quality Planning and Standards, RTP, NC, CAIR Docket OAR-2005-0053-2149

U.S. Environmental Protection Agency (2006a) Final regulatory impact analysis: $\mathrm{PM}_{2.5}$ NAAQS. Prepared by Office of Air and Radiation. Available at http://www.epa.gov/ttn/ecas/ria.html. Accessed 10 March 2008

U.S. Environmental Protection Agency (2006b) Technical support document for the Final PM NAAQS Rule. Office of Air Quality Planning and Standards, Research Triangle Park, NC

U.S. EPA (2008) Final ozone NAAQS regulatory impact analysis. Office of Air and Radiation, Research Triangle Park, NC, March, Ozone Docket EPA-HQ-OAR-2007-0225-0284

Woods and Poole Economics, Inc. (2007) Population by single year of age CD. CD-ROM. Woods \& Poole Economics, Inc., Washington, DC 